\title{
LOS PRINCIPIOS INVERTIDOS: LA IRREVOCABILIDAD Y RETROACTIVIDAD DE LOS ACTOS ADMINISTRATIVOS EN EL ÁMBITO TRIBUTARIO
}

\section{Guzmán Ramírez*}

\begin{abstract}
RESUMEN. En el ámbito del Derecho Administrativo son aceptados los principios de revocabilidad eirretroactividad de los actos de la Administración. Pero aquí analizaré cómo estos dos principios fundamentales pueden invertirse, y su incidencia en el área tributaria, para concluir en: (i) la imposibilidad de la Administración Tributaria de modificar sus actos de determinación en el sentido de generarle al contribuyente un mayor gravamen (salvo en determinados casos excepcionales), y (ii) la retroactividad de los actos administrativos que conllevan la aprobación de la inscripción registral (y consecuente reconocimiento) de entidades exoneradas de impuestos.
\end{abstract}

PALABRAS CLAVES- Irrevocabilidad. Retroactividad. Acto administrativo. Determinación tributaria.

ABSTRACT. In the field of Administrative Law, standards of revocability and non-retroactivity of the acts of Government are accepted. However, I will herein analyze how this two basic standards may be reversed, and its implications within taxation, in order to conclude with: (i) the inability of the Tax Administration to amend its re-assessment resolutions in the sense of triggering a higher burden on the taxpayer (except in certain exceptional cases), and (ii) the retroactivity of administrative acts involving the approval of registration (and the consequent acknowledgment) of tax-exempted entities.

KEYWORDS. Non-revocability. Retroactivity. Administrative act. Tax re-assessment resolution.

* Profesor de Derecho Tributario Universidad ORT. Correo electrónico: gramirez@bergsteinlaw.com 


\section{La facultad de la Administración Tributaria de revocar los actos de determinación, y su vinculación con los principios de seguridad jurídica y buena fe.}

\subsection{Análisis introductorio.}

En 2018, varios montevideanos - propietarios de inmuebles ubicados en la periferia del Departamento- fueron sorprendidos cuando recibieron sus facturas de Contribución Inmobiliaria. Vieron incrementado, de manea exponencial, el monto del impuesto a pagar. Ello obedeció fundamentalmente a un cambio en la categorización de sus inmuebles: antes calificaban como rurales; ahora pasaron a considerarse sub-urbanos. Dicha re-categorización generó dos (2) consecuencias de particular trascendencia: (i) un cambio en el régimen tributario: los inmuebles comenzarían a tributar Contribución Inmobiliaria Urbana/SubUrbana (no más Contribución Inmobiliaria Rural), y (ii) un importante incremento del valor de aforo considerado para el cálculo del impuesto.

Para mayor sorpresa, la Intendencia pretendió no solamente aplicar dichos cambios hacia el futuro (esto es, a partir de 2018), sino que también pretendió hacerlo con efecto retroactivo, re-liquidando los impuestos pagos en 2016 y 2017.

Más allá del "absurdo jurídico" de pretender cobrar sobre un mismo inmueble dos (2) impuestos que son incuestionablemente incompatibles (un inmueble puede ser categorizado como rural - y en consecuencia tributar Contribución Inmobiliaria Rural-, o como urbano/suburbano - y en consecuencia tributar Contribución Inmobiliaria Urbana/Suburbana; pero la Intendencia no puede hacer tributar un inmueble como rural y luego pretender hacerlo tributar como urbano/sub-urbano por el mismo período), el planteo realizado por la Intendencia de Montevideo resulta propicio para reflexionar — con una perspectiva más amplia - acerca de la posibilidad o imposibilidad de cualquier Administración Tributaria (no solamente la Intendencia) de modificar los actos de determinación previamente dictados por ella.

Todos estamos de acuerdo con que los actos administrativos — de principio— pueden ser revocados o modificados por la Administración, sea a petición del interesado o incluso de oficio. Esto es lo que se conoce como "principio de revocabilidad de los actos administrativos". En palabras de SAYAGUÉS LASO, "la situación de la Administración ante sus propios actos irregulares es muy especial. En principio... luego de constatado el vicio la Administración puede extinguir el acto mediante revocación. Esto se justifica por cuanto

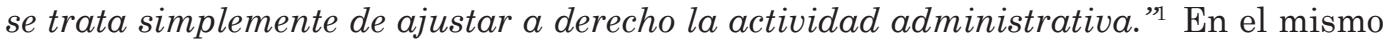
sentido, Alberto Ramón REAL sostenía: "El acto administrativo es, en principio, revocable y no pasa en autoridad de cosa juzgada. Aún cuando sea firme, no admita más recursos o haya sido consentido, es revocable de oficio y le es oponible la excepción de ilegalidad."2

Pero dicho principio se invierte cuando el cambio que pretende la Administración, es en perjuicio del contribuyente. La Administración Tributaria —en principio— no puede modificar un acto de determinación en el sentido de generarle al contribuyente un mayor

SAYAGUÉS LASO, Enrique. Tratado de Derecho Administrativo Tomo I (2010), p. 421.

2 REAL, Alberto Ramón. "Extinción del acto administrativo creador de derechos", en Revista de la Facultad de Derecho y Ciencias Sociales N 1-2 (1960), p. 94. 
gravamen (sí puede hacerlo para reducirlo), salvo en determinadas circunstancias a las que referiré más adelante.

Elementales razones de seguridad jurídica así lo imponen. Como bien dicen Gianni GUTIÉRREZ y Alberto VARELA, "la seguridad jurídica se encuentra en la base misma del Derecho, integrando su concepto y en consecuencia constituye un principio general que debe considerarse inherente a todo Estado de Derecho y a la personalidad humana. La finalidad primaria del Derecho es hacer posible la convivencia social pacífica, asegurar la paz y el orden dentro de una sociedad, para lo cual el Derecho debe introducir cierto grado de certeza en las relaciones entre los miembros de la sociedad.’’

De conformidad con dicho principio general, no es jurídicamente posible que en un momento dado la Administración Tributaria haya obligado al contribuyente a pagar una determinada suma de dinero, y luego pretenda acrecentar dicha suma por la vía de volver a dictar otro acto de determinación modificativo del anterior.

Dicha conclusión aplica para todos los actos de determinación. Aplica cuando dicho acto ha sido dictado por la Administración luego de una inspección fiscal (esto es, luego de que el contribuyente presentara su correspondiente declaración jurada). Pero mucho más aplica en el caso de la determinación de oficio (como sucede en la Contribución Inmobiliaria). Pues en este caso el contribuyente no tiene ninguna incidencia ni injerencia en la liquidación del tributo, sino que simplemente se limita a pagar — de buena fe_la suma de dinero determinada por la Administración, depositando su confianza en la presunción de que dicha determinación ha sido realizada correctamente.

Entonces también está involucrado el principio de buena fe. Jonás BERGSTEIN explica que "la buena fe es uno de los grandes fundamentos del Derecho todo. No se concibe un Estado de Derecho que no reconozca en la buena fe uno de sus lineamientos vectores o directrices principales. Un Derecho que no estuviera dominado por ese principio, no sería Derecho, o en todo caso sería un Derecho injusto."

Como consecuencia de dicho principio general, hay que tener en cuenta que en la determinación de oficio, la iniciativa es exclusiva de la Administración. La Administración Tributaria — sin la intervención del contribuyente - determina la cuantía de la obligación tributaria en función de los elementos que ella misma dispone (como sucede con el valor de aforo de los inmuebles, en el caso de la Contribución Inmobiliaria). Si es la Administración la que dispone de todos los elementos necesarios para cuantificar la obligación tributaria, dicha Administración debe respetar la buena fe de los contribuyentes, que lo único que hacen es limitarse a pagar la cifra oportunamente determinada por la Administración.

\subsection{Respaldo de la doctrina.}

Los mayores expertos en Derecho Tributario han tenido la oportunidad de analizar el tema, principalmente haciendo referencia a los actos de determinación dictados luego de una inspección fiscal — previa declaración jurada del contribuyente—. Pero — según

3 GUTIÉRREZ, Gianni; y VARELA, Alberto. La Carta de Derechos del Contribuyente en Uruguay (2008), p. 111.

4 BERGSTEIN, Jonás. Buena fe y Derecho Tributario (2018), p. 8. 
expliqué más arriba—sus conclusiones son enteramente extrapolables a la determinación de oficio.

Todos ellos están de acuerdo en la imposibilidad de la Administración de modificar los actos de determinación tributaria en perjuicio del contribuyente (salvo en algunas hipótesis de excepción).

VALDÉS COSTA sostenía: “...Los actos administrativos en materia tributaria...deben tener cierta estabilidad juridica como requisito indispensable para dar a los interesados las debidas garantias propias del Estado de Derecho. ...Todos estamos de acuerdo en que los actos administrativos...tienen que tener estabilidad juridica, por diversas razones, entre ellas fundamentalmente por la aplicación del principio de la seguridad juridica. ${ }^{95}$

Francisco MARTÍNEZ compartía el mismo pensamiento: “. . El acto únicamente puede alterarse si la ley lo permite; pero lo consiente solo de dos maneras: en beneficio del deudor cuando. . la autoridad realiza un nuevo examen; $y$, en contra del deudor, en caso de que por su culpa, por una violación de los deberes que le incumben en el procedimiento preparatorio o como consecuencia de otros hechos contrarios a la ley, la determinación se ha hecho incompleta, esto es, en el caso de fraude; fuera de estos supuestos el acto es intangible.'"

Queda claro pues que, en el caso de un acto de determinación de oficio (como el de la Contribución Inmobiliaria) no podría darse ninguna de las situaciones que podrían autorizar a la Administración Tributaria a modificar dicho acto en perjuicio del contribuyente. MARTÍNEZ menciona la posibilidad de la Administración Tributaria de hacerlo, pero ello cuando el contribuyente hubiere cometido algún acto de fraude o ilegalidad. Tal extremo no podría verificarse en el caso de una determinación de oficio como la que la Intendencia realiza en materia de Contribución Inmobiliaria. Todo lo contrario. En estos casos, el contribuyente no hace más que pagar de buena fe el impuesto determinado por la Intendencia. No podría atribuírsele ninguna ilegalidad, ni mucho menos fraude.

En la misma línea de pensamiento, el argentino GIULIANI FONROUGE sostenía: "Aunque la determinación de la obligación fiscal no es un acto de indole jurisdiccional y, por lo tanto, no puede hablarse de cosa juzgada a su respecto, la certeza del derecho -que es uno de sus fines- exige que una vez considerados los elementos informativos del caso y exteriorizada la opinión de la autoridad administrativa, ella no pueda ser alterada discrecionalmente si fue puesta en conocimiento del deudor o responsable y aceptada por este. El acto puede ser modificado antes, pero no después de la notificación, pues una vez puesto en conocimiento del particular afectado, el acto ha salido del campo unilateral de la administración, engendrando un derecho por parte de aquel al mantenimiento de la situación creada... Es incuestionable el derecho del Fisco a modificar la determinación, cuando se descubren nuevas circunstancias o antecedentes que fueron sustraidos al conocimiento de la Administración o, mejor dicho, cuando por acción u omisión del deudor o responsable (culpa o dolo), el órgano estatal no pudo disponer de todos los elementos necesarios para la correcta determinación del

5 VALDÉS COSTA, Ramón. Estudios de Derecho Tributario Latinoamericano (1982), pp. 174 y 175.

6 Citado por Ramón VALDÉS COSTA en Estudios de Derecho Tributario Latinoamericano (1982), p. 172. 
tributo, como es el caso del contribuyente que oculta bienes, que omite denunciar réditos o comunicar documentos que influyen en el monto imponible... En consecuencia, para modificar la determinación firme, es necesario que el error haya sido ocasionado por el proceder del contribuyente o responsable, o que razonablemente pueda imputársele... Consideramos inadmisible la revisión del acto de determinación consentido, por la circunstancia de que los funcionarios administrativos hayan incurrido en errónea apreciación de datos y elementos conocidos en oportunidad, pues como ha dicho la Corte Suprema, no es obligación de los particulares fiscalizar, controlar o apercibir al Estado por el descuido o ineficacia de sus empleados... Con el mismo propósito de certeza del derecho y estabilidad de los negocios juridicos... el contribuyente no debe satisfacer ningún suplemento de impuesto en tanto la deficiencia no obedezca a mala fe, culpa o dolo de su parte... Únicamente es admisible la rectificación de errores materiales o aritméticos (no de concepto) que no pudieron pasar inadvertidos para el particular, como sería el caso-por ejemplo- de que en los fundamentos del acto se haga mención de una cifra y en la parte dispositiva se consigne un importe menor del que aritméticamente corresponda, o exista un error de suma o transposición de números."

En definitiva — dice GIULIANI FONROUGE-la Administración podría modificar el acto de determinación previamente dictado cuando el error yacente en dicho acto fuese el resultado de la mala fe del contribuyente. GIULIANI FONROUGE también dice que la modificación del acto de determinación podría admitirse en perjuicio del contribuyente cuando dicho error fuese meramente aritmético (y no de concepto), y además fuese tan notorio/evidente que no podría haber pasado inadvertido por el contribuyente. Fuera de estos casos, prevalece la irrevocabilidad en perjuicio del contribuyente del acto de determinación.

Tampoco la Administración podría justificar la modificación de un acto de determinación tributaria - en perjuicio del contribuyente - invocando un eventual error de sus funcionarios. Decía el tributarista italo-argentino Dino JARACH: "Debe excluirse... la posibilidad de... modificación de la determinación, cuando la Administración misma sin la existencia de hechos imputables a los administrados, haya cometido errores de hecho o de derecho en su pronunciamiento. En otras palabras la norma en cuestión no permite (al Fisco) modificar posteriormente sus decisiones para subsanar sus propias deficiencias."

El también argentino Héctor B. VILLEGAS afirmaba: “. . Los efectos de la resolución determinativa deben ser diferentes para el Fisco que para el sujeto pasivo, debiendo quedar el primero ligado en mayor medida que el segundo a dicha resolución... Mientras los derechos impugnativos del sujeto pasivo son amplios y solo se encuentran limitados por el principio de legitimidad del acto determinado, la Administración queda vinculada al resultado arribado, y si el acto fue notificado al determinado y reunió las condiciones esenciales para su validez (forma y competencia), la decisión determinativa tendrá efectos preclusivos para la Administración en cuanto a su evaluación de los elementos para ella conocidos al momento de determinar.'

GIULIANI FONROUGE, Carlos. Derecho Financiero Volumen I (1987), pp. 562 y ss.

JARACH, Dino. Finanzas Públicas y Derecho Tributario (1983), p. 449.

9 VILlEGAS, Héctor B. Curso de Finanzas, Derecho Financiero y Tributario (1997), p. 346. 
El mexicano DE LA GARZA reafirmaba estos conceptos diciendo: “...Dictada $\boldsymbol{y}$ notificada la liquidación, ésta no puede modificarse en perjuicio del contribuyente..."10

Finalmente, el peruano Humberto MEDRANO CORNEJO informa que "la resolución de determinación tiene que ser única, integral y definitiva. Una vez notificada, sin que el contribuyente interponga recursos impugnatorios, la misma ya no puede ser modificada... Permitir que se emita una nueva resolución de determinación para incluir reparos que no se hicieron al informarse la resolución original, llevaría a la incertidumbre absoluta, pues a pesar de haberse notificado deuda por un cierto monto que el contribuyente acepta expresamente, el Fisco podría ampliar su exigencia en función de objeciones que no hizo en la ocasión anterior. Esta operación podría repetirse de manera indefinida, con lo cual desaparecería por completo la seguridad jurídica. Por tales razones, nosotros consideramos que no deben admitirse las resoluciones "provisionales" pues ello permitiría fiscalizar una y otra vez al mismo período con relación al mismo tributo. Lo contrario implicaria ingresar en el reino de la inseguridad y la indefensión... Con ello se eliminaría cualquier viso de certeza respecto del cumplimiento de las obligaciones impositivas. Se trata de un planteamiento inaceptable que otorgaria a la Administración la facultad de dejar sin efecto las notificaciones previamente cursadas para modificarlas cuantas veces considere conveniente. .. Se infringiría el principio de seguridad jurídica, toda vez que se autorizaría a la Administración para revocar, modificar, sustituir o complementar sus actos en cualquier circunstancia... Los hechos habilitantes para la modificación deben originarse en una actuación del contribuyente que hubiera impedido al Fisco tomar conocimiento de la existencia de la obligación o liquidar con exactitud el monto del tributo. Es decir que tales hechos deben consistir en actos que para la Administración son nuevos, y que, por razones imputables al contribuyente, le resultó imposible conocer. . . De lo expuesto se sigue, que el contribuyente no es responsable de la ineficacia de los empleados del Fisco."11

MEDRANO CORNEJO, en opinión que comparto, destaca que los actos de determinación provisionales no son admitidos en Derecho Tributario, por resultar contrarios al principio de seguridad jurídica. En consecuencia, incluir en los actos de determinación tributaria una mención a que la Administración se reserva el derecho a re-liquidar los tributos determinados, debería considerarse nula y —en consecuencia— tenerse por noescrita.

Además, el pago de cualquier impuesto determinado por la Administración Tributaria, tiene pleno efecto cancelatorio. Lo dice PÉREZ NOVARO refiriéndose específicamente a la Contribución Inmobiliaria: “...Cuando el contribuyente no participa en la fijación o liquidación de la obligación tributaria, tal como ocurre por ejemplo con la Contribución Inmobiliaria... en el ámbito departamental, el pago efectuado tiene pleno valor cancelatorio."

${ }^{10}$ DE LA GARZA, Sergio. Derecho Financiero Mexicano (1968), p. 750.

${ }^{11}$ MEDRANO CORNEJO, Humberto. "Límites a la fiscalización: prescripción e intangibilidad de las acotaciones notificadas", en Revista Ius et Veritas $N^{\circ} 31$ (2005), pp. 23 y ss. 
El mismo PÉREZ NOVARO continúa diciendo: "Hay situaciones en que el sujeto activo aplica un nuevo valor imponible al bien gravado. El nuevo valor deberá resultar de mutaciones operadas en el inmueble... lo que requiere una nueva apreciación directa por parte del organismo avaluador y configura el dictado de un nuevo acto administrativo, susceptible de impugnación por los propietarios. Dicho nuevo valor del bien no debe aplicarse retroactivamente, pues se agrederia el principio de la irretroactividad de los actos administrativos, asi como el de que los cambios de criterios impositivos perjudiciales para el contribuyente rigen siempre para el futuro, de acuerdo... al principio de seguridad juridica..."

Y finalmente concluye: "Que la Administración liquide y cobre un impuesto en base a los valores reales fictos y que luego pretenda re-liquidarlos, implica un cambio de criterio que debe ser notificado al contribuyente para que éste ejerza las defensas que considere aplicables y como todo cambio de criterio más gravoso para el contribuyente debe ser aplicado para el futuro, nunca retroactivamente." 12

\subsection{Conclusión.}

Corresponde subrayar aquí que no se trata de cuestionar la facultad de la Administración Tributaria de revocar/modificar sus actos administrativos. Sí se trata de impedir que la Administración Tributaria ejerza dicha facultad (revocatoria) en desconocimiento del principio de seguridad jurídica y en violación de la buena fe y confianza del contribuyente.

\section{La eficacia retroactiva de los actos administrativos declarativos y su repercusión en la inscripción registral de las entidades exoneradas de impuestos}

\subsection{Análisis introductorio}

Es cierto que los actos administrativos — de principio - tienen efectos no-retroactivos. Pero esto no quiere decir que no haya excepciones. Lo reconoce el propio SAYAGUÉS LASO: "Generalmente el acto administrativo produce efectos para el futuro, es decir, no tiene efecto retroactivo. ...Pero esto no excluye que en ciertos casos pueda tener efectos hacia el pasado, cuando la ley expresamente lo autoriza o cuando la retroactividad es el efecto natural del acto." 13

Una de estas excepciones está representada por los actos administrativos que tienen naturaleza declarativa. El principio de irretroactividad de los actos administrativos se invierte en los casos de actos administrativos declarativos. Los actos administrativos de naturaleza declarativa tienen efectos retroactivos cuando producen efectos favorables al interesado y no lesionan derechos o intereses legítimos de otras personas. Si partimos de la base de que un acto administrativo declarativo tiene por objeto reconocer una situación pre-existente (esto es, una situación que existía antes del dictado de dicho acto), solo es posible concluir que los efectos de dicho acto se retrotraen al momento desde el que dicha situación — que fue declarada tal por la Administración—en la realidad existía.

12 PÉREZ NOVARO, César. Modos de Extinción de la Obligación Tributaria (2005), pp. 88 y 89.

13 SAYAGUÉS LASO, Enrique. Tratado de Derecho Administrativo Tomo I (2010), p. 498. 
No es posible escindir la naturaleza declarativa de un acto administrativo, de los efectos que dicho acto conlleva. Y ello por cuanto la naturaleza declarativa de un acto administrativo es definida precisamente por sus efectos. En la medida que un acto administrativo reconoce una situación que pre-existía a su dictado, tenemos que concluir que dicho acto tiene efectos retroactivos.

\subsection{Respaldo de la doctrina.}

La doctrina (tanto nacional como extranjera) admite que los efectos de los actos administrativos declarativos se retrotraen al pasado.

Así lo enseña DURÁN MARTÍNEZ, quien —al referirse a los actos de naturaleza declarativa - ha dicho: “...Este tipo de actos son necesariamente retroactivos." 14

En el mismo sentido, se expresa el tratadista argentino MARIENHOFF: "En mérito... al fundamento que le atribuyo a la irretroactividad del acto administrativo, éste resultará retroactivamente aplicado cuando aparezca reglando hechos, conductas o situaciones anteriores a la fecha de su vigencia..."15

Y finalmente el jurista español MARTÍN MATEO comparte dicha opinión: "Normalmente, los actos producen sus consecuencias hacia el futuro, no hacia el pasado, pero también excepcionalmente pueden tener eficacia retroactiva cuando... produzcan efectos favorables al interesado, siempre que los supuestos de hecho necesarios existieran ya en la fecha a que se retrotraiga la eficacia del acto." 16

\subsection{Respaldo de la jurisprudencia.}

El nexo entre la naturaleza declarativa de un acto administrativo y su eficacia retroactiva, ha sido reconocido por la jurisprudencia. Y tiene especial trascendencia en el orden tributario, particularmente en lo que refiere al acto que la Administración dicta al aceptar la inscripción en el registro de una entidad exonerada de impuestos.

La Sentencia $N^{\circ}$ 41/2017 del Tribunal de Apelaciones en lo Civil de $7^{\circ}$ Turno (del 19 de abril de 2017) adhiere a la tesis de que un acto administrativo declarativo despliega sus efectos hacia el pasado.

En este caso, una institución inscripta en el Registro de Instituciones Culturales y de Enseñanza del Ministerio de Educación y Cultura (MEC), promovió una acción de repetición de pago contra la Dirección General Impositiva (DGI). Dicha institución entendía que correspondía se le devolviesen los impuestos pagos con anterioridad a dicha inscripción, bajo la premisa de que el acto administrativo que había aprobado dicha inscripción tenía efectos declarativos y por ende retroactivos.

El Tribunal de Apelaciones en lo Civil de $7^{\circ}$ Turno (integrado por los Dres. Cristina Cabrera, Edgardo Ettlin y Beatriz Tommasino) expresó que “. . habrá de amparar la pretensión de autos. .. Estamos ante una inscripción de naturaleza declarati-

14 DURÁN MARTÍNEZ, Augusto. "Retroactividad del acto administrativo", en Anuario de Derecho Administrativo Tomo VII (1999), p. 84.

15 MARIENHOFF, Miguel. Tratado de Derecho Administrativo Tomo II (1966), p. 393.

16 MARTÍN MATEO, Ramón. Manual de Derecho Administrativo (2005), p. 256. 
va...Permite constatar una realidad existente con anterioridad a la inscripción. La redacción del Artículo 69 de la Constitución en futuro ("estarán exoneradas") no significa que la inmunidad esté supeditada a una inscripción administrativa... La redacción en tal tiempo verbal es parte de la técnica legislativa con la que suelen redactarse las normas. ...La inscripción de la institución de enseñanza privada o cultural, no se hace en el MEC para gestionar una exoneración tributaria, sino para dar cuenta de su existencia y de su seriedad... En consecuencia, cuando el Estado cobra tributos a dichas instituciones, lo hace ilegítimamente. Si les cobró estos conceptos y luego se constata que la institución estaba en condiciones de ser sujeto de la inmunidad tributaria, debe devolver lo percibido..."

En definitiva, el Tribunal de Apelaciones obligó a la DGI a devolver los impuestos pagos antes de la inscripción (esto es, admitió que el acto declarativo también aplicaba hacia el pasado).

\subsection{Conclusión.}

Entiendo que no pueden existir dos lecturas al respecto. Los actos administrativos declarativos reconocen una situación pre-existente, y en cuanto reconocen una situación pre-existente, no están alcanzados por el principio de irretroactividad de los actos administrativos. Dichos actos (declarativos) no despliegan sus efectos jurídicos exclusivamente hacia el futuro, sino también hacia el pasado, en tanto favorezcan al interesado y no perjudiquen a otras personas. La inscripción en el registro de una entidad exonerada de impuestos, está comprendida entre dichos actos.

\section{BIBLIOGRAFÍA CONSULTADA.}

BERGSTEIN, Jonás. Buena fe y Derecho Tributario (2018).

DE LA GARZA, Sergio. Derecho Financiero Mexicano (1968).

DURÁN MARTÍNEZ, Augusto. "Retroactividad del acto administrativo", en Anuario de Derecho Administrativo Tomo VII (1999).

GIULIANI FONROUGE, Carlos. Derecho Financiero Volumen I (1987).

GUTIÉRREZ, Gianni; y VARELA, Alberto. La Carta de Derechos del Contribuyente en Uruguay (2008).

JARACH, Dino. Finanzas Públicas y Derecho Tributario (1983).

MARIENHOFF, Miguel. Tratado de Derecho Administrativo Tomo II (1966).

MARTÍN MATEO, Ramón. Manual de Derecho Administrativo (2005).

MEDRANO CORNEJO, Humberto. "Límites a la fiscalización: prescripción e intangibilidad de las acotaciones notificadas", en Revista Ius et Veritas No 31 (2005).

PÉREZ NOVARO, César. Modos de Extinción de la Obligación Tributaria (2005).

REAL, Alberto Ramón. "Extinción del acto administrativo creador de derechos", en Revista de la Facultad de Derecho y Ciencias Sociales N 1-2 (1960).

SAYAGUÉS LASO, Enrique. Tratado de Derecho Administrativo Tomo I (2010).

VALDÉS COSTA, Ramón. Estudios de Derecho Tributario Latinoamericano (1982).

VILLEGAS, Héctor B. Curso de Finanzas, Derecho Financiero y Tributario (1997).

Fecha de recepción: 15 de marzo 2019.

Fecha de aceptación: 17 de marzo 2019. 
